\title{
THE PHENOMENON OF MATCH-FIXING IN FOOTBALL
}

\author{
Korneliya Naydenova \\ National Sports Academy "Vassil Levski" (Bulgaria)
}

\begin{abstract}
One aspect of the security of sport, which is rarely considered by the organizers of sports events, concerns the different manifestations of match-fixing. The match-fixing of the result of a sports event or any component of it contradicts the established norms and values of the sporting competition, drawn up at the end of the XIX century by Baron Pierre de Coubertin and known as Olympism. Today, match-fixing is one of the phenomena in modern sport. Advertising, publicity, profit largely regulate relations in professional sport, and in full force, this applies to football as the most popular sport in the world.

If we look at what has been said so far through the prism of Bulgarian football, it is enough to look at the Bulgarian football championships, whose official sponsor is an online betting company at sporting events and the first football league is named after this company. This same company has sponsorship relations with more than 10 football clubs, and to them we can add the volleyball and basketball federations, as well as some of the brightest representatives of these federations.

Noticing this trend of business entering the sport, we set out to explore the opinion of players and their coaches about the manifestation of the phenomenon of match-fixing in Bulgarian football. The results of the survey show the existence of match-fixing at both professional and amateur level and allow us to indicate some steps to prevent such non-sporting techniques from winning.
\end{abstract}

Keywords: football; match-fixing; footballers; coaches

\section{Introduction}

The overall change in the way of life and development of society caused changes in the field of sports. Today, sport is not the only activity that brings satisfaction with movement. Sport is a motor activity, it is a spectacle, work, some claim it is health, others are of the opposite opinion. In addition to the athlete, coach and audience today actively participate in the sport have scouts, analysts, managers, journalists, doctors, lawyers, fans, bookmakers and more, and more. This is very clear in football, which as the most popular sport in the world leads to the realization of huge cash flows. Proof of this is developed by the consulting 
company Deloitte "Football League of Money". According to the 24rd edition of this ranking of the football clubs with the highest revenues in the $2019-2020$ season is Barcelona, which generated revenues of 715,1 million euros, followed by Real Madrid with 691,8 million, and the German Bayern Munich 634,1 million, slightly more generated of the twenty most profitable clubs in the world revenues amounted to 8,2 billion euros. (Deloitte 2021).

Looking at these figures, we realize that today in football we are talking mainly about transfers, profits, sponsors, owners of football clubs, etc. The emphasis in a football match shifts from purely sporting arguments to financial ones. The financial side and the repeated interpretations of concepts such as fair play, rules, respect, values, sports competition have led to the emergence of new trends and concepts, to the problems of modern sports related to breaking all rules and the emergence of phenomena such as doping, black lotto, corruption. According to O. Brodkin (2020), match-fixing for the purpose of winning bets in the world of sports happens every day. In support of this statement, we can point to the biweekly Interpol reports (Interpol 2021), addressing various acts of breach of integrity in sport. In two of these reports from March and April 2021 (Interpol 2021) more than 10 similar cases were considered. Investigations and punishments have been reported from around the world. Serbia, the United States, Chile, Venezuela, Thailand, the Netherlands, the UAE, which violate the rules of integrity and have settled the final results or individual elements not only of football matches, but also in sports such as basketball, tennis, cricket, darts and even reported cases of match-fixing in various electronic sports.

\section{Purpose}

Examining the above facts, we have some ambiguities, on the phenomenon of match-fixing in Bulgarian football. To complete these ambiguities, we set out to study the opinion of footballers and coaches from different levels of Bulgarian football, regarding the presence and different manifestations of arranging matches in the country.

To achieve this goal, we set ourselves the following tasks:

1. Study of the considered problem in literary and documentary sources.

2. Conducting a survey with football players and coaches from professional and amateur football.

3. Derivation of the differences in the manifestation of the settlement of matches between the different target groups of subjects.

\section{Methodology}

The contingent of the study included a total of 68 players and coaches with an average age of 33 years and 7 months. The distribution of the contingent according to their professional profile is presented in the following table (Table 1). 
Table 1. Research contingent

\begin{tabular}{|l|c|c|c|}
\hline & Coaches & Football players & Total \\
\hline Professionals & 21 & 22 & 43 \\
\hline Amateurs & 10 & 16 & 26 \\
\hline Total & 31 & 38 & 69 \\
\hline
\end{tabular}

The developed questionnaire is aimed at studying the opinion and understandings of the surveyed contingent of persons regarding the match-fixing, the manifestation of the phenomenon under consideration in different levels of Bulgarian football, the views of respondents on penalties for participation in activities related to matchfixing and ways to prevention of such actions. We conducted the survey at the end of 2019 online, through the Google Forms tool, which ensured the anonymity of the survey. The sample is not representative.

The results of the study were processed by SPSS v.23, using one-dimensional and two-dimensional frequency distribution. The reliability of the revealed differences was verified by the correlation coefficient for alternative variables $\mathbf{F}$ and its adjacent guarantee probability.

\section{Results}

In the analysis of the results obtained from the study, we divide the research contingent into groups corresponding to their role in football, coaches or football players and corresponding to their status professionals or amateurs. The chosen approach allows us to consider and analyze the perceptions of the respondents about the phenomenon of match-fixing from four different points of view.

We start the analysis of the obtained results with the answers of the respondents to the question "In your opinion, how serious is the problem with match-fixing?", And they should give an answer according to their understanding of the problem in both professional and amateur football. Their assessment corresponds to a scale from 1 to 5 , with 1 being the lowest level and 5 the highest level of manifestation of the seriousness of the considered problem.

According to the results presented in Figure 1, we should note the presence of an alarming trend showing the existence of match-fixing in Bulgarian football. Interpreting the presented percentages, we believe that the manifestation of the phenomenon of match-fixing in both professional and amateur football is at a high level. This assumption of ours is supported by the total low percentage of answers of the respondents who fall at the bottom of the scale and exceeding in almost all cases the percentage of answers 4 and 5. For example, for professional football the cumulative percentage of answers at the bottom of the scale is $17,6 \%$, and in the upper, where answers 4 and 5 fall is $53,6 \%$. Analyzing the answers to the same 


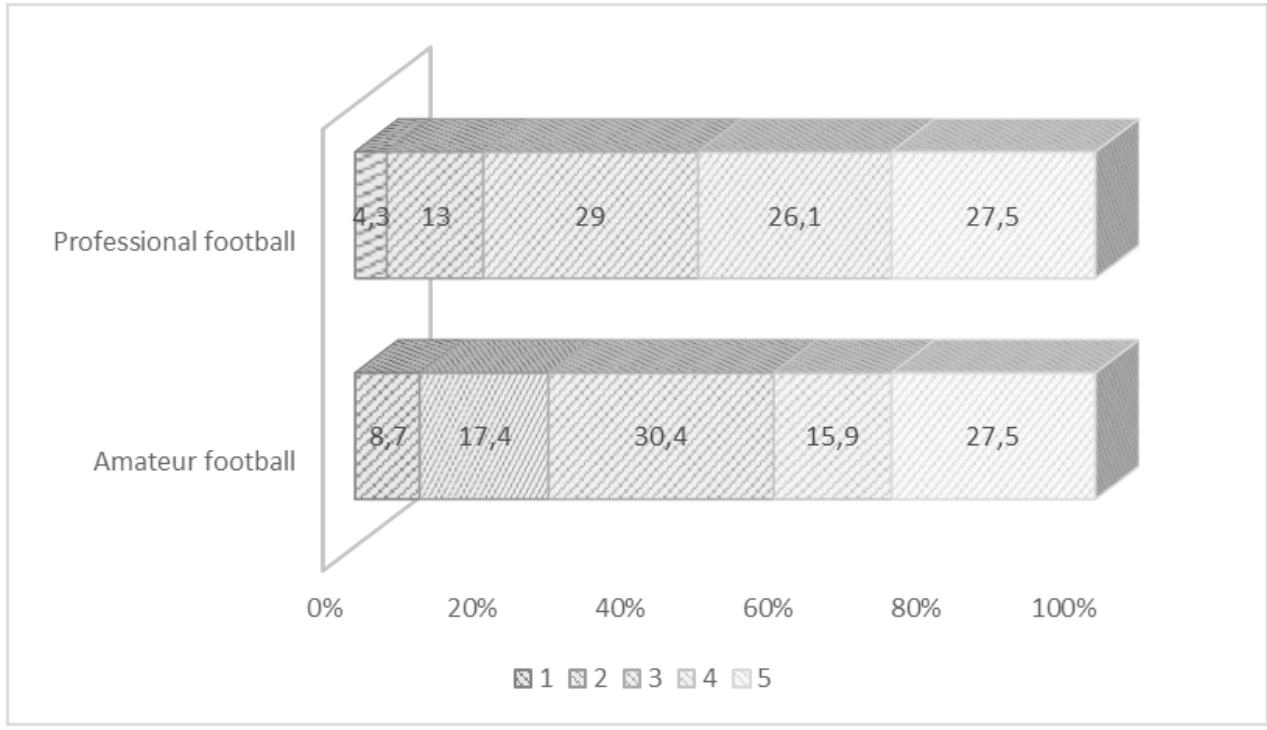

Figure 1. Percentage distribution of answers to the question "In your opinion, how serious is the problem of match-fixing?"

question, but in amateur football, these percentages are distributed, respectively, $26,1 \%$ vs. $43,4 \%$.

Looking at the answers to the above question, but comparing the answers of coaches and players, we can say that among coaches the problem of match-fixing is more common in professional football. As opposed to them, among the surveyed athletes, the considered problem is equally relevant for amateur and professional football in the country. The figures of our statements are 35,6\% of the coaches surveyed, who gave a score of 4 or 5 in terms of the seriousness of the problem of arranging matches in amateur football, compared to $56,1 \%$ in professional football. For the competitors, these answers are $50 \%$ of the given ones.

Relating this question not to the status, but to the league in which the respondent participates, the answers acquire the form presented in Figure 2.

The figure clearly shows the high percentage of coaches in amateur football $(60 \%)$, who indicate answers 4 and 5 to the question. Regarding the coaches from the first and second professional leagues, this percentage is significantly lower $-38.1 \%$. For competitors, this trend is the opposite. According to $36.3 \%$ of the players from the two professional leagues, the problem can be defined as serious and even very serious. And $56.3 \%$ of the football players, but from the amateur championships of Bulgarian football define the problem as seriously manifested. 


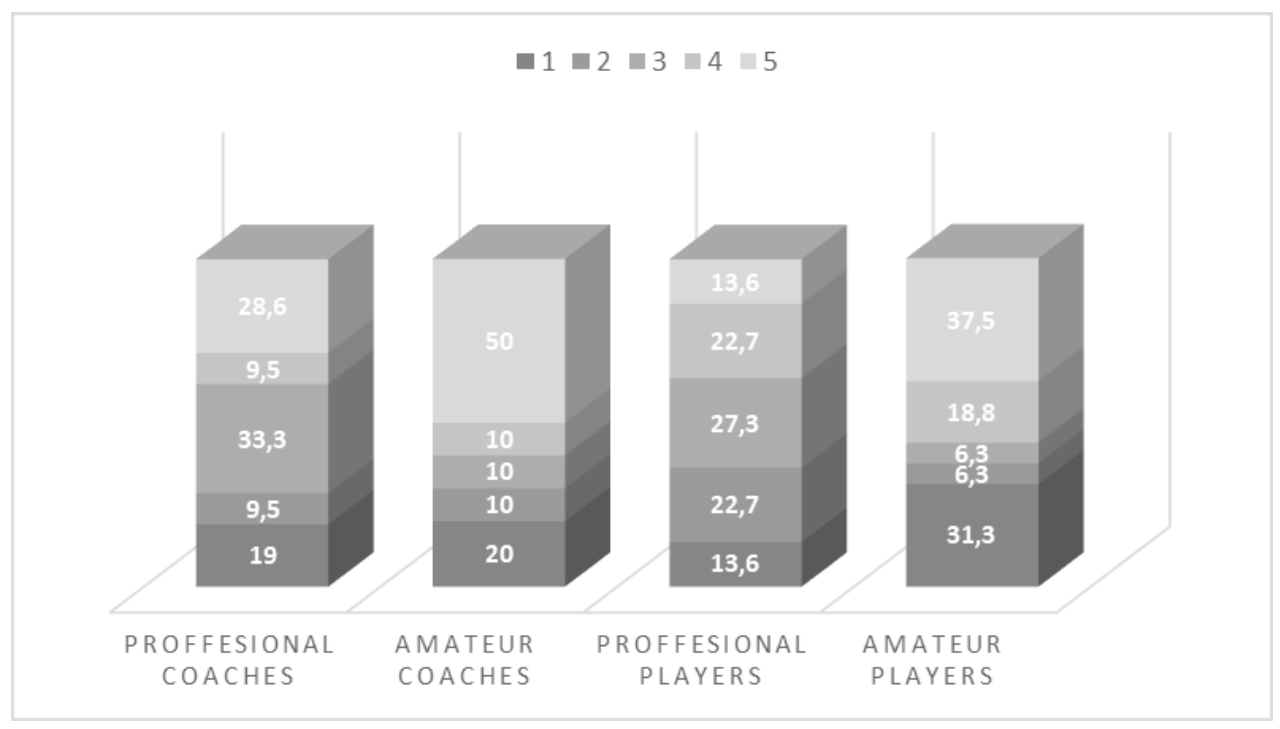

Figure 2. Percentage distribution of answers to the question "To what extent do you think match-fixing is a problem in the league you are participate?"

In order to establish the attitude of the respondents to the considered problem, we included in the questionnaire the question "In your opinion, what is the monetary threshold that would motivate a player or other interested party in arranging football matches in the league in which you compete?". The answers here show the existence of a rather low financial incentive, which would motivate a participant in a football match to participate in various activities aimed at settling the result of a match or its individual components. In the case under consideration, $61 \%$ indicated an answer to EUR 5,000, which is the lower monetary threshold that we indicated in the survey. The upper threshold, which amounts to 30,000 euros, was given by only $15 \%$ of respondents. More disturbing for us are the answers that four of the respondents indicated, in addition to the other option there are amounts from 100 to 1000 euros, which are essentially quite low for football standards and opportunities that players in the market of sports betting play out.

Studying the answers given to the commented question, as well as the answers to the previous three questions, we could summarize that in view of the percentage distribution of answers and low monetary thresholds indicated by the respondents, match-fixing has a stronger manifestation in amateur football where salaries of coaches and athletes are at and slightly above the level of the minimum wage. This summary is confirmed by the two-dimensional frequency distribution, where 53\% 
of respondents in the field of amateur football, according to which the problem of arranging matches in the league in which they participate is serious or very serious, answered that the amount that would motivate a participant in a football match to participate in match settlement procedures is in the range of 100 to 500 euros. In professional football, this percentage is 40 , and the answers given are no such amount or 100,000 euros.

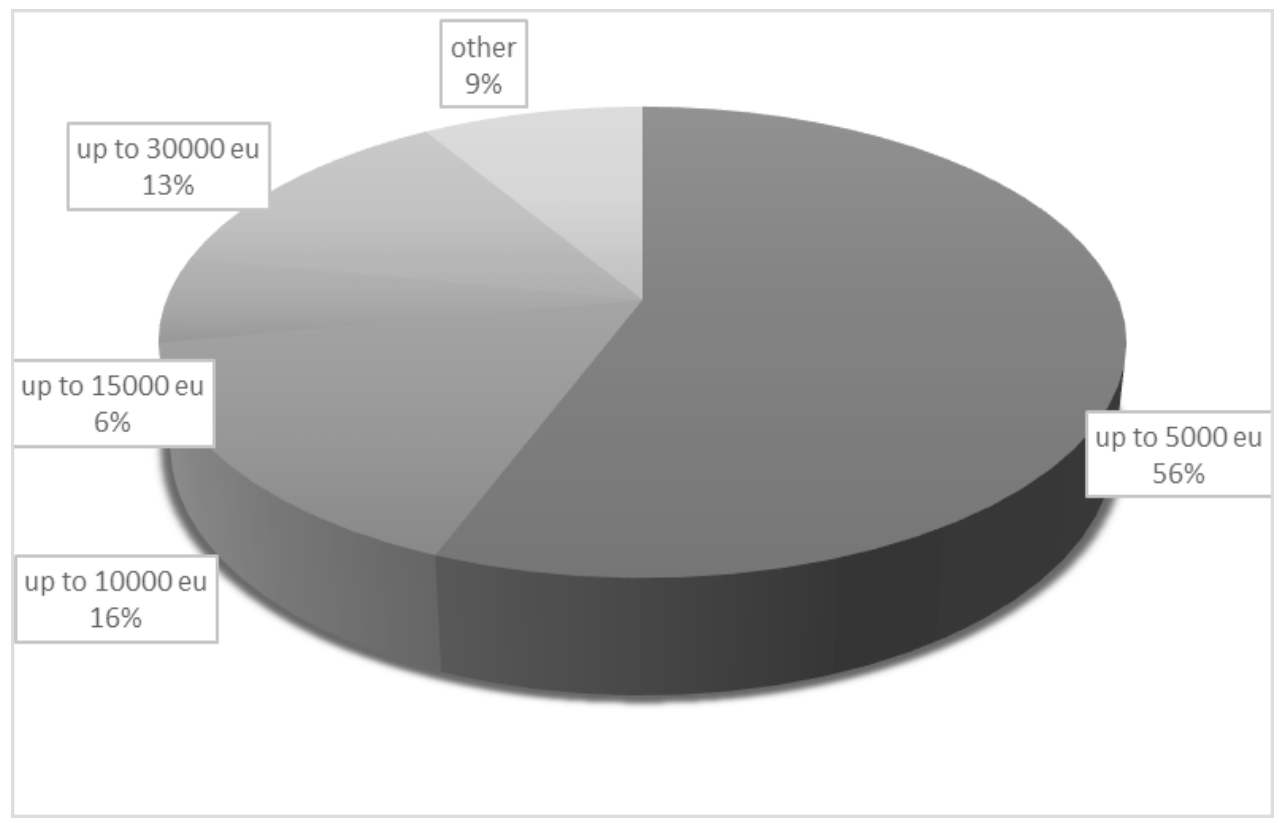

Figure 3. Percentage distribution of answers to the question "In your opinion, what is the monetary threshold that would motivate a player or other stakeholder to fix matches in the league in which you are competing?"

We are also interested in the actions that the interested parties would take in the event of an offer to influence the outcome of a match or the manipulation of its individual components. The results presented in Figure 4 allow us to again draw the differences between the manifestation of the problem at the professional and amateur level. Both coaches $(55,6 \%)$ and amateur football players $(62,5 \%)$ would in most cases report to the competent authorities only if they are sure that there will be no consequences for them. As a positive in view of the counteraction to match-fixing, we should point out the high percentage $(68,2 \%)$ of professional football players who will report in any case, regardless of the consequences. 


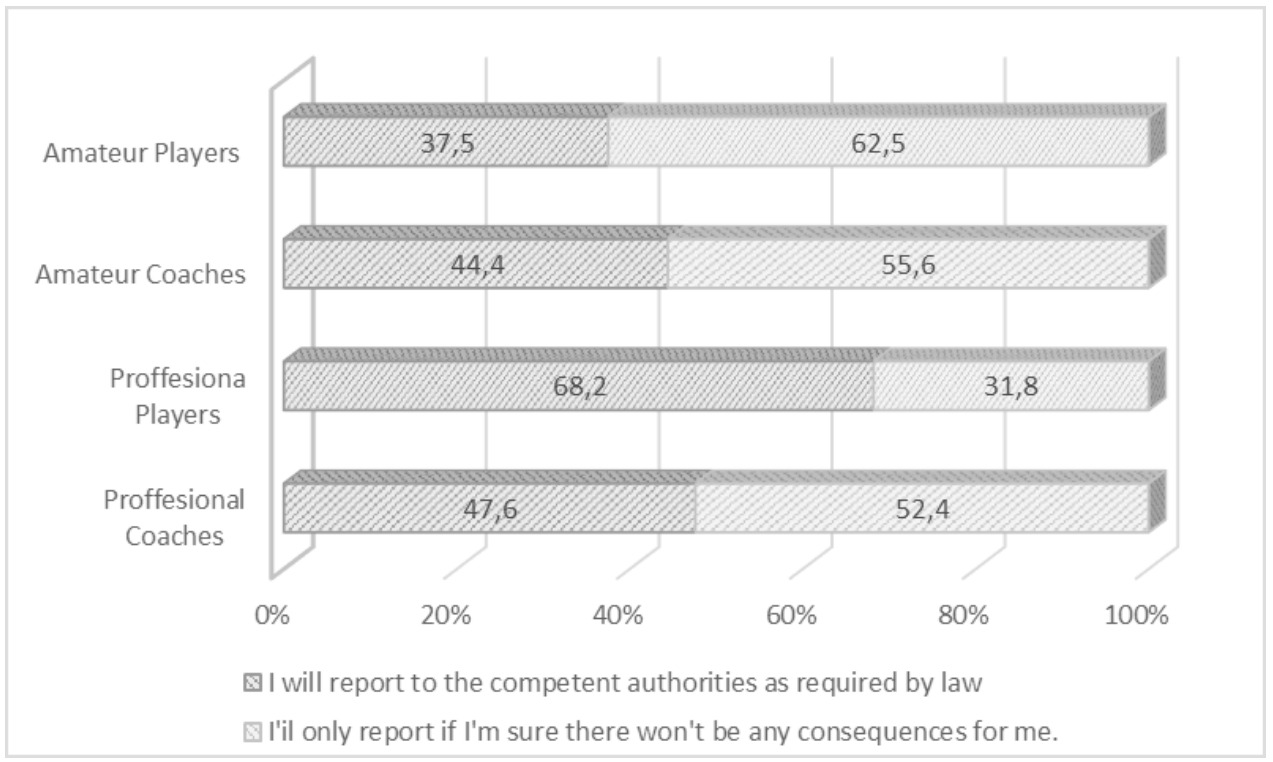

Figure 4. Percentage distribution of answers to the question "If someone suggested you participate in match-fixing, how would you react?"

How they would report and the possible consequences for the participants in settling matches are the next issues we discussed with the respondents. When asked which authorities they will turn to in case they are offered to participate in match-fixing, the respondents give different answers. $21,7 \%$ of them answer $\mathrm{BFU}, 34,8 \%$ intend to turn to the police, another $18,8 \%$ combine the previous two answers, $22,4 \%$ will turn in one way or another to the club, having in mind the coach, the manager, the president, etc., and 2,9\% will report to UEFA or FIFA. The data distributed in this way do not direct us to a specific object to be determined as the most preferred by the respondents, which allows us to assume that the respondents or at least most of them are not familiar with the protocol for reporting in case or on suspicion of manipulating matches but would rather trust a familiar person.

This assumption of ours is confirmed by the distribution of the answers to the next question asked, namely "In which of the following ways would you report on the settlement of matches?". In $68,1 \%$ of cases, respondents would report through personal contact with a competent person, almost the same percentage $14,5 \%$ and $13 \%$ would report via email or phone call.

Respondents' attitudes towards the phenomenon of match-fixing are clear in the answers they gave to the question "What should be the consequences under 
criminal law or disciplinary rules in football for players, other stakeholders and football clubs involved in match-fixing?". Here, respondents were given eight different options for response, which ranged from the lightest presumed warning to the most severe possible imprisonment. $43,5 \%$ of the respondents believe that in a proven case the punishment for the person should be "Temporary or life ban from participation in football events". Approximately the same percentage of 15,9 and 14,5 were indicated by the answers "Imprisonment or suspended sentence" and "Financial penalties and fines". The remaining answers remain in the range below $8 \%$, which shows the uncompromising attitude of the respondents towards the problem under consideration.

Asked, "What do you think are the most effective measures to prevent matchfixing?", Respondents arranged the possible measures, believing that the best results would be measures such as: encouraging players, coaches and other stakeholders to report any evidence or indications for match settlement; improving existing provisions and laws, in particular improving sanctions; improving information and communication between all stakeholders on risks and sanctions, as well as wider negative consequences. On the other hand, measures such as the appointment or election of a sports ombudsman and the appointment or election of an employee responsible for integrity in a club or football association would not, in the respondents' view, be particularly effective in counteracting the phenomenon in question.

\section{Discussion}

Reflecting on the analysis of the results obtained from the study, we can summarize that the phenomenon of match-fixing should be defined as a serious problem in Bulgarian football. The opinion of the respondents points us to the fact that the manifestation of this phenomenon is equally high in both amateur and professional football. We attribute this fact to the peculiarities of the financial stimulation of the players and coaches in football in Bulgaria and paradoxes regarding the payment and management of the football clubs. This is the reason for the low levels of financial incentives indicated by coaches and players, which, in their opinion, are sufficiently motivating to take part in procedures for arranging matches or individual components of football matches.

Based on the analyzes made, we believe that changes are needed in terms of club and national policies in terms of prevention and combating match-fixing in Bulgarian football. In view of the opinion of the respondents, we could recommend regular trainings with the various stakeholders - both at the level of the football club and at the level of the Bulgarian Football Union, which should be aimed at acquainting the athletes with the legal framework and its consequences for them in cases of attempts to manipulate the result of a football game or of its individual components. 


\section{REFERENCES}

Brodkin., O., 2020. Ghost Games: Un Explanantion. [Online] Available at: https://www.sportradar.com/ [Retrieved on 28 April 2021].

Deloitte, 2021. Testing Times: Football Money League. https:/www2. deloitte.com/uk/en/pages/sports-business-group/articles/deloittefootball-money-league.html [Online] Available at: https://www2. deloitte.com// [Retrieved on 25 May 2021].

Interpol, Integrity in Sport, Bi-weekly Bulletin, 16-29 March, 2021. https:// www.interpol.int/en/Crimes/Corruption/Corruption-in-sport.

Available at: https://www.interpol.int [Retrieved on 26 April 2021].

\section{Korneliya Naydenova}

ORCID iD: 0000-0001-8084-1069

Department of Theory of Physical Education National Sports Academy "Vassil Levski"

Sofia, Bulgaria Email: knaidenova.nsa@gmail.com 